\title{
Dutch General Practitioners' weight management policy for overweight and obese patients
}

\author{
Corelien JJ Kloek ${ }^{1 *}$, Jacqueline Tol ${ }^{1}$, Cindy Veenhof ${ }^{1}$, Ineke van der Wulp ${ }^{2}$ and IIse CS Swinkels ${ }^{1}$
}

\begin{abstract}
Background: General practitioners (GPS) can play an important role in both the prevention and management of overweight and obesity. Current general practice guidelines in the Netherlands allow room for GPs to execute their own weight management policy.

Objective: To examine GPs' current weight management policy and the factors associated with this policy.

Methods: 800 Dutch GPs were asked to complete a questionnaire in December 2012. The questionnaire items were based on the Dutch Obesity Standard for GPs. The data were analyzed by means of descriptive statistics and multiple linear regression analyses in 2013.

Results: In total, 307 GPs (39.0\%) responded. Most respondents (82.9\%) considered weight management as part of their responsibility for providing care. GPs aged $<48$ years discussed weight less frequent. Next, weight is less frequently discussed with patients without weight-related comorbidities or with moderately overweight patients compared to obese patients. On average, $47.7 \%$ of the GPs reported to refer obese patients to a weight management professional, preferably a dietitian (98.3\%). GPs with a BMI $\geq 25 \mathrm{~kg} / \mathrm{m}^{2}$ were less likely to refer obese patients. In addition, GPs who had frequent contact with a dietitian were more likely to refer obese patients.

Conclusions: In the context of General Practice and preventive medicine, GPs' discussion of weight and the variety of obesity-determinants with their moderately overweight patients deserves more attention, especially from younger GPs. Strengthening interdisciplinary collaboration between GPs and dietitians could increase the referral percentage for dietary treatment.
\end{abstract}

Keywords: Obesity, General practitioners, Public health, Referral and consultation

\section{Background}

Overweight and obesity constitute a global problem, denoted by the World Health Organization (WHO) as "globesity". In 2008, 35\% of the adults worldwide were overweight, defined as a Body Mass Index (BMI) of $25.0-30.0 \mathrm{~kg} / \mathrm{m}^{2}$ and additionally $12 \%$ of the adults were obese, defined as a $B M I \geq 30.0 \mathrm{~kg} / \mathrm{m}^{2}[1]$. The number of people with overweight and obesity has increased rapidly in recent decades. In the Netherlands alone, the prevalence of adults with overweight increased from $28.2 \%$ to $36.8 \%$ between 1981 and 2011. In addition, the prevalence of obesity doubled from $5.3 \%$ to $11.4 \%$ during the same period [2]. Without preventive action it is estimated that overweight and obesity in the

\footnotetext{
* Correspondence: c.kloek@nivel.nl

'NIVEL Utrecht, PO Box 1568, 3500 BN, Utrecht, The Netherlands

Full list of author information is available at the end of the article
}

Netherlands may affect two thirds of the adult population by 2024 [3]. As a consequence, Dutch healthcare costs directly related to overweight and obesity are substantial [4]. Overweight and obesity are important risk factors for chronic diseases like Type 2 Diabetes Mellitus, cardiovascular diseases, different types of cancer (endometrial, breast, colon) osteoarthritis [5] and are related to poorer quality of life [6]. In addition, obesity is significantly associated with major depressive disorders and anxiety disorders [7].

As gatekeepers in the Dutch health care system, General Practitioners (GPs) can play an important role in both the prevention and management of overweight and obesity. Nearly $80 \%$ of all Dutch citizens visit their GP at least once a year [8]. People with obesity consult their GP more often than those without obesity [9]. Guidelines for GPs' weight management policy are outlined in the Obesity Standard 
of the Dutch College of General Practitioners (NHG). Diagnostics and treatment are indicated for patients with a $B M I \geq 25.0 \mathrm{~kg} / \mathrm{m}^{2}$, weight-related comorbidities or increased cardiovascular risks. For overweight patients with an excessive waist circumference, diagnostics and treatment are only indicated if weight is the patient's reason for consultation. Treatment may consist of counseling about nutrition, physical exercise, motivation, and discussion about environmental influences, psychosocial problems and weight-related health risks [10]. Referral to other health care providers (i.e. dietitian or nurse practitioner) is indicated in the following situations: if requested by the patient, if underlying causes such as psychological problems are suspected, if previous attempts to lose weight have failed or if the patient needs comprehensive support [10].

Previous studies have shown that GPs intervene in terms of diagnostics and treatment in only half of the patients with obesity, but specific information about The Netherlands is missing [11,12]. Barriers among GPs to discussing weight with their patients were a lack of time, insufficient knowledge, inadequate skills, lack of confidence and insufficient motivation among patients [13-20]. Female doctors were more likely to deliver weight-related counseling and were more prevention orientated in obesity management compared to their male colleagues [21]. Also GPs' age has been shown to be related to their attitude regarding weight management policy, although results are inconsistent [22,23]. Finally, GPs who themselves were conscious of their personal diet, appeared to calculate patients' BMI more frequently [14].

With regard to the referral percentage of patients with obesity for nutrition and/or dietary advice, previous studies have reported a relationship with GPs' attitude toward other health care providers. Mathus-Vliegen et al. reported that because of some GPs' negative attitude to dietitians, they often do not refer patients with obesity to these health care providers [24]. Moreover, problems with interdisciplinary communication impede GPs from referring overweight and obese patients $[17,24,25]$. Costs involved with dietary treatment were cited as a further inhibiting factor in referring patients to other health care providers for nutrition and/or dietary advice [26].

Clearly, the increasing prevalence and the seriousness of overweight and obesity highlight the necessity for solutions. Because of their central role in primary care, GPs are regarded as the principal health care providers in the management of overweight and obesity. Although guidelines for weight management are contained in the NHG Obesity Standard, there is a lack of information about GPs' weight management policy in daily practice. Multiple factors have been found to be associated with GPs' weight management policy, however there may be other influencing factors related to the GP, which may be informative in improving weight related referral rates. New in this study is the combination of the survey of GPs' current weight management policy and the analysis of the factors associated with this policy. The objective of the present study is to explore GPs' policy on the management of overweight and obesity as well as factors associated with this policy.

\section{Methods}

\section{Design and study population}

This study was conducted in a cross-sectional design. A random sample of 800 registered Dutch GPs representative of gender, age, type of employment, type of practice and degree of urbanicity were invited to participate. The GPs were recruited from the national register database for primary health care providers of the Dutch Institute for Health Services Research (NIVEL) [27]. Those working as temporary employees were excluded from the study. According to the Dutch Medical Research Involving Human Subjects Act this study did not require ethics approval.

\section{Data collection}

The data were collected by means of a questionnaire measuring GPs' weight management policy. For the purpose of this study several questions were developed and included in a larger postal survey. The complete questionnaire included 26 questions (12 were used for the current study, see Additional file 1). The 26 questionnaire items (Additional file 1) were based on the National Obesity Standard for GPs [10]. The items were measured on either a ratio, ordinal or nominal level. The questionnaire comprised two sections of which the first included general questions with regard to overweight and obesity. The second section focused on patients with obesity solely, because an intervention is always indicated for these patients [10]. Nine researchers provided reviews on the scope, length and comprehensibility of the questionnaire. After these expert evaluations, minor modifications were made. The questionnaire was sent by post in December 2012 and took approximately 10 minutes to complete. A reminder was sent in January 2013.

\section{Statistical analysis}

Data analysis was performed using Stata version 12 (StataCorp LP, College Station, Texas, USA) in 2013. The results were processed anonymously. Based on the NIVEL database, general details were available on the GPs who did not participate. Non-response analyses were performed by using t-tests and Chi-squared tests. Missing values were excluded in the analyses. The answer "do not know" was treated as a missing value. Assumptions of statistical techniques were checked. 
GPs' policy on managing overweight and obesity was determined by means of descriptive statistics on questionnaire items 1, 2, 3, 4 and 10 (Additional file 1).

The frequency of discussing weight was determined by adding up the respondents' answers on item 2 (7 subitems, 4-point scaled) of the questionnaire. The possibility of merging these 7 different sub-items was investigated by using the Spearman correlation test and a calculated Cronbach's alpha. Items with $-0.80<\mathrm{r}<0.80$ were merged, as these item associations were considered (fairly) strong. Likewise, a Cronbach's alpha score of $>0.70$ was considered as good internal consistency [28]. The generated sum score for "discussing weight" ranged from 7 to 28 points, where higher scores indicated that GPs more often discussed weight with their patients.

Characteristics associated with GPs' policy, i.e. the dependent variables, discussing weight sum score and referral percentage for nutrition and/or dietary advice, were analyzed univariately in separate analyses, by means of t-tests and Chi-squared tests. Independent variables were GPs' gender, age, type of employment, BMI, vision about duties of care, perception of other health care providers' suitability for weight management, frequency of contact with a dietitian, type of practice and degree of urbanicity. Independent variables with $\mathrm{p}<0.15$ in univariate analyses were included in a multiple linear regression model. In the case of absence of linearity between the independent and dependent variables, 5-point scaled items were transformed into 3-point scaled items. In the case of linearity, continuous variables were centered to the mean for better interpretation. In multivariable analysis a, $\mathrm{p}<0.05$ was considered as statistically significant.

\section{Results}

\section{Respondents and non-respondents}

Of the 800 questionnaires distributed, 12 were returned because of incorrect addressing or because the GPs appeared to be retired. From the final sample of 788 GPs, the net response rate was $39.0 \%(\mathrm{~N}=307)$. Table 1 presents the characteristics of those who participated in the survey compared to the non-respondents. Nonresponse analyses showed no statistically significant differences between respondents and non-respondents. Table 2 shows the results of the questionnaire. On average, GPs' BMI appeared to be $23.5 \mathrm{~kg} / \mathrm{m}^{2}$ (SD 2.6; min-max: $\left.17.4-31.7 \mathrm{~kg} / \mathrm{m}^{2}\right)$. Nearly a quarter $(24.9 \%)$ of the GPs were overweight.

\section{GPs' vision and frequency of discussing weight}

Figure 1 shows GPs' perception about overweight and obesity management. Most respondents (82.9\%) agreed that promoting a healthy weight is an important part of GP care. Likewise, a majority (90.8\%) agreed that GPs should educate patients with obesity about potential
Table 1 General characteristics of respondents and non-respondents

\begin{tabular}{|c|c|c|c|}
\hline Variable & $\begin{array}{l}\text { Respondents } \\
\mathrm{n}=307(39.0 \%)\end{array}$ & $\begin{array}{l}\text { Non-respondents } \\
n=481(61.0 \%)\end{array}$ & $\begin{array}{l}\text { p-value non- } \\
\text { response analysis }\end{array}$ \\
\hline \multicolumn{4}{|l|}{ Gender ${ }^{a}:$} \\
\hline Male & 142 (51.4\%) & 246 (51.1\%) & 0.93 \\
\hline Female & $134(48,6 \%)$ & 235 (48.9\%) & \\
\hline Age, mean & 48.3 (SD 9.2) & 47.9 (SD 8.8) & 0.63 \\
\hline$<40$ & 71 (23.1\%) & $100(20.8 \%)$ & \\
\hline $40-49$ & 91 (29.7\%) & 164 (34.1\%) & \\
\hline$\geq 50$ & 145 (47.2\%) & 217 (45.1\%) & \\
\hline \multicolumn{4}{|c|}{$\begin{array}{l}\text { Type of } \\
\text { employment }{ }^{\mathrm{a}} \text { : }\end{array}$} \\
\hline Private & 226 (81.9\%) & 416 (86.5\%) & 0.09 \\
\hline Salaried & $50(18.1 \%)$ & 65 (13.5\%) & \\
\hline \multicolumn{4}{|l|}{$\begin{array}{l}\text { Type of } \\
\text { practice: }\end{array}$} \\
\hline Solo & 60 (19.5\%) & 90 (18.7\%) & 0.45 \\
\hline Dual & 119 (38.8\%) & 208 (43.2\%) & \\
\hline Group & $128(41.7 \%)$ & 183 (38.1\%) & \\
\hline \multicolumn{4}{|c|}{ Urbanicity $^{\text {b: }}$} \\
\hline Urban & 158 (51.5\%) & 158 (46.4\%) & 0.31 \\
\hline Suburban & $56(18.2 \%)$ & $56(18.5 \%)$ & \\
\hline Rural & 93 (30.3\%) & 93 (35.1\%) & \\
\hline
\end{tabular}

${ }^{\mathrm{a}} \mathrm{N}=276$ Respondents.

bUrbanicity: Urban: $\geq 1500$ addresses per km²/Suburban: 1000-1499 addresses per $\mathrm{km}^{2} /$ Rural: $<1000$ addresses per $\mathrm{km}^{2}$.

health risks. A smaller percentage (53.8\%) agreed that GPs should discuss weight, even if the obese patient has another reason for the consultation. Figure 2 shows GPs' reported frequency of discussing weight for different stages of overweight and obesity. GPs were less likely to discuss weight with patients who had lower BMI and/or no weight-related health risks.

\section{Weight-related topics discussed by the GP}

Weight-related topics that were most frequently broached by GPs during consultations were patients' motivation for weight loss $(84.0 \%)$, amount of physical exercise (81.4\%), weight-related health risks (77.5\%), nutrition pattern $(72.3 \%)$ and weight loss efforts in the past (67.1\%). Additionally, 57.7\% of the GPs reported to discuss possible interventions to achieve weight loss. Less often discussed by GPs were patients' current medication use (21.5\%), psychosocial problems (32.3\%) and environmental influences on weight (35.5\%).

The two most frequently reported reasons for not talking about weight with an obese patient were "already talked about weight in the past" (76.9\%) or "not having enough time" (59.9\%). Patients lacking motivation (24.4\%) and 
Table 2 General results from questionnaire

\begin{tabular}{lll}
\hline Variable & $\mathbf{N}^{\mathbf{c}}$ & $\%$ \\
\hline GPs' BMI: $^{\prime}$ & & \\
$<25$ & 217 & 75.1 \\
$\geq 25$ & 72 & 24.9
\end{tabular}

Frequent contact with a dietitian:

$\begin{array}{lll}\text { No } & 164 & 54.0 \\ \text { Yes } & 140 & 46.0\end{array}$

Specialized health care providers in building ${ }^{\mathrm{a}}$ :

$\begin{array}{lll}\text { No } & 50 & 16.3\end{array}$

$\begin{array}{lll}\text { Yes } & 257 \quad 83.7\end{array}$

Dietitian in building:

No $\quad 166 \quad 54.1$

$\begin{array}{lll}\text { Yes } & 141 & 45.9\end{array}$

GPs' perception of health care provider suitability $^{\mathbf{b}}$ :

-GP:

Not at all/somewhat

Mainly/very suitable

$98 \quad 32.8$

-Nurse practitioner:

Not at all/somewhat

Mainly/very suitable

-Dietitian:

Not at all/somewhat

Mainly/very suitable

-Weight-management consultant:

Not at all/somewhat

Mainly/very suitable

-Psychologist:

Not at all/somewhat

Mainly/very suitable

-Physical therapist:

Not at all/somewhat

Mainly/very suitable

$87 \quad 29.1$

$212 \quad 70.9$

$5 \quad 1.7$

29598.3

${ }^{\mathrm{a}}$ Health care providers who deliver nutritional and/or dietary advice.

${ }^{b}$ Suitability of providing weight management for obese patients.

'Due to missing values, $\mathrm{N}$ differs per question.

"afraid to negatively influence the relationship with the patient" (23.1\%) were less frequently cited.

\section{Factors associated with frequency of discussing weight}

The mean score for GPs discussing weight sum score was 21.1 (SD 2.7; min-max: 14-28). In univariate analyses, GPs' age and their vision about promoting a healthy weight as an important part of GP care, were associated $(\mathrm{p}<0.15)$ with the discussing weight sum score. Table 3 shows the results from the multiple linear regression model. The discussing weight sum score increased by 0.06 points for every year that the GP's age was above the mean of 48 years. Further, GP's vision about promoting a healthy weight as an important part of GP care, was related to the frequency of discussing weight. The discussing weight sum score increased by 0.71 points for every point (on a 5-point scale) that GPs agreed more with the assertion that promoting a healthy weight is an important part of GP care.

\section{Collaboration with other health care providers for weight management}

Most GPs (83.7\%) reported the presence of one or more health care providers specialized in nutrition and/or dietary advice in the same medical center. Nearly half (46.0\%) reported having frequent contact with a dietitian. The majority $(98.3 \%)$ regarded the dietitian as a suitable health care provider for the dietary treatment of patients with obesity. Nearly a third (32.8\%) of GPs regarded themselves as a suitable health care provider for obesity treatment (Table 2). Most frequently reported reasons for not referring to a dietitian were lack of patients' motivation for weight loss $(63.8 \%)$, the fact that patients did not want to receive help from a dietitian (54.7\%) and high costs of dietitian consultations (38.1\%).

\section{Referral percentage for obesity management and associated factors}

GPs' average self-reported referral percentage of patients with obesity to other health care providers for nutrition and/or dietary advice was $47.7 \%$ (SD 27.8).

Univariate analyses showed that GPs' BMI, frequent contact with a dietitian, the presence of a dietitian in the same medical building, vision of educating patients with obesity about weight-related comorbidities and discussing weight with patients were associated with the referral percentage for obesity management $(\mathrm{p}<0.15)$.

Table 4 shows the results from the multiple linear regression model. Overweight or obese GPs (BMI $\geq 25)$ were significantly related to an $11.6 \%$ lower referral percentage for obesity management compared to those with a healthy weight. GPs'frequently in contact with a dietitian were significantly related to an increase of $11.8 \%$ in referral rate compared to GPs who were not frequently in contact with a dietitian. GPs who agreed with the assertion that educating patients with obesity about weight-related comorbidities is part of GP care reported a significantly higher referral percentage (24.1\%) for obesity management.

\section{Discussion and conclusion}

This explorative study showed that most GPs (82.9\%) considered weight management for overweight and obese patients as part of their responsibility for providing care. However, weight is less frequently discussed by younger GPs. Next, weight is less frequently discussed with patients 


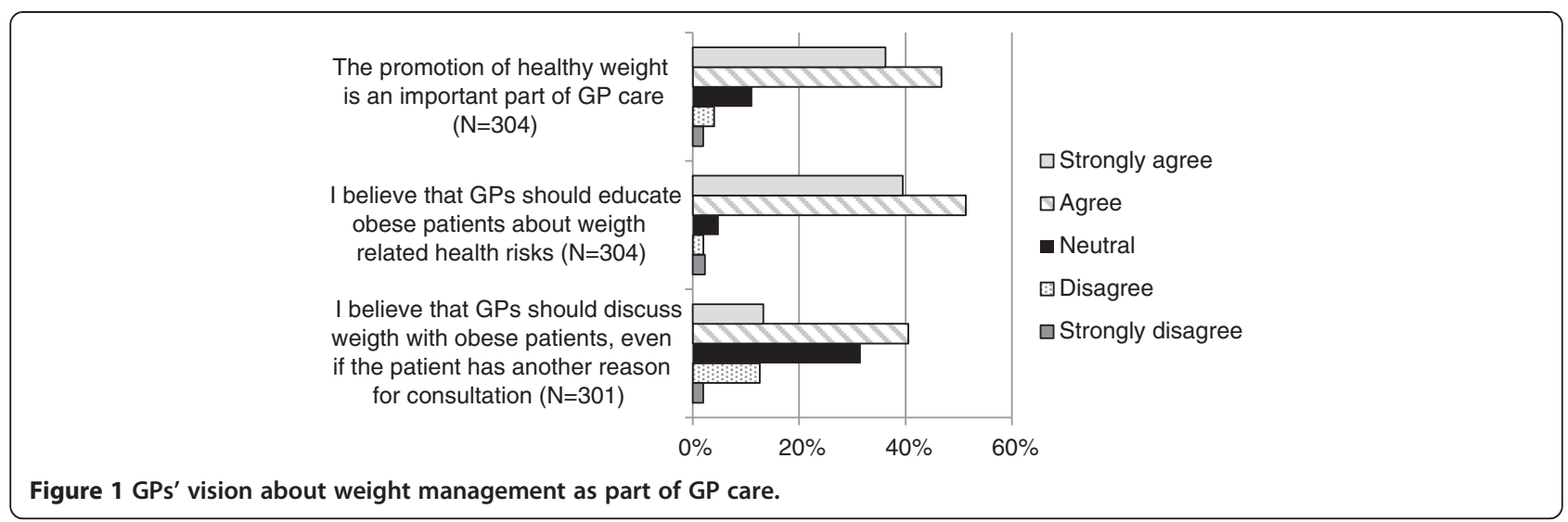

without weight-related comorbidities or with moderately overweight patients compared to obese patients. Nearly half of the GPs reported to refer obese patients to a weight management professional, preferably a dietitian. In addition, GPs who had frequent contact with a dietitian and those who felt more responsible for educating patients with obesity about weight-related comorbidities were more likely to refer obese patients. Finally, overweight and obese GPs were less likely to refer obese patients. The results of this study may be used to improve consistency in GPs' weight management policy, for example, by means of communication and education materials.

This paper identified three major findings. First, GPs' weight management policy appeared to be less targeted on primary prevention, neither on the social-environmental factors of overweight and obesity. The result that GPs are less involved in the weight management of people with moderate weight problems is in accordance with a study of Smith et al. [29]. Nonetheless, discussing weight to create awareness at an early stage of weight gain is important as this is the first step in behavioral change [30]. Besides, it is plausible to assert that reaching a healthy weight is easier at an early stage of weight gain. In addition, discussing the influence of medication use, psychosocial problems and environmental factors on patient's weight management should be encouraged, as these appeared to be talked about less frequently. The importance of these topics is frequently described in the literature. For example, overeating is a common coping mechanism in emotional distress [31]. The environmental availability of healthy or unhealthy food is related to individuals' food choices [32].

A second major finding of this study is that GPs' personal characteristics such as age, BMI and concerns appeared to be related to their reported weight management policy. Part of these findings may be explained by the reported negative attitudes towards obese patients among younger GPs [22]. Similar to the findings of Brotons et al., [33] a relationship between GPs' BMI and frequency of discussing weight was absent. Possibly, overweight and obese GPs do not believe in an effective treatment of obesity in general. However, this should be studied further. From a patient's perspective, overweight or obese GPs negatively affect credibility, level of trust and intention to follow weight management advice [34]. Therefore, GPs need to be aware of how they can act as a positive health role model by having a healthy BMI themselves. Finally, GPs who believed that promotion of a healthy

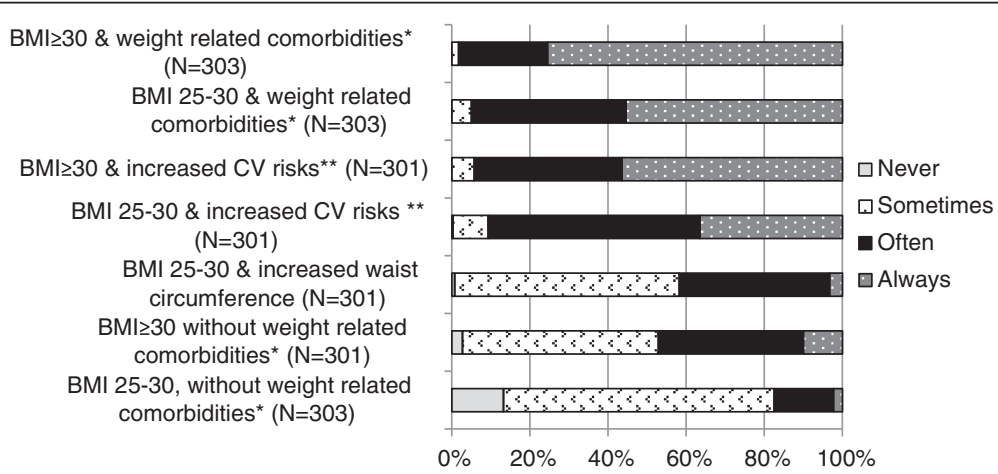

Figure 2 Frequency of discussing weight during consultations, for different populations. * For example osteoarthritis, DMII. **For example familial cardiovascular diseases, high blood pressure. 
Table 3 Multiple regression model of GP-related factors associated with discussing weight (scale $7-28)(N=303)$

\begin{tabular}{lll}
\hline Variable & Coefficient $(\mathbf{9 5 \%}$ C.I.) & p-value \\
\hline Age (mean): & $0.06(0.03 ; 0.10)$ & $<0.01$ \\
$\begin{array}{l}\text { Vision about GPs' duties of care: } \\
\text {-Promoting healthy weight as }\end{array}$ & $0.71(0.37 ; 1.05)$ & $<0.01$ \\
$\begin{array}{l}\text { an important part of GP care: } \\
\text { Intercept }\end{array}$ & $18.13(16.70 ; 19.56)$ & \\
\hline
\end{tabular}

weight is an important part of GP care likewise discussed weight more often. This implies that, in order to increase GPs frequency of discussing weight, GPs' consciousness of weight management as part of their care should be stimulated, recommended by others as well [35]. With respect to this study that investigated the relationship between GPs' characteristics and their weight management policy, there is a lack of information about the relationship between patients' characteristics (e.g. age, sex, social economic status) and GPs' weight management.

A third important finding is that GPs weight management policy can be improved on several ways. Only half of GPs refer their obese patients to other health care providers for dietary treatment and weight is not always discussed, although guidelines recommend doing it. GPs reported several reasons for not talking about weight, with

Table 4 GP-related factors associated with referrals for obesity management $(\mathrm{N}=\mathbf{2 4 8})$

\begin{tabular}{|c|c|c|}
\hline Variable & $\begin{array}{l}\text { Coefficient } \\
(95 \% \text { C.I.) }\end{array}$ & p-value \\
\hline \multicolumn{3}{|l|}{ GPs' BMI: } \\
\hline$<25$ & Reference & Reference \\
\hline$\geq 25$ & $-11.6(-19.5 ;-3.7)$ & $<0.01$ \\
\hline \multicolumn{3}{|c|}{ Frequent contact with a dietitian: } \\
\hline No & Reference & Reference \\
\hline Yes & $11.8(4.2 ; 19.3)$ & $<0.01$ \\
\hline \multicolumn{3}{|c|}{ Dietitian in building: } \\
\hline No & Reference & Reference \\
\hline Yes & $0.9(-6.6 ; 8.5)$ & 0.81 \\
\hline \multicolumn{3}{|c|}{$\begin{array}{l}\text { Vision about GPs' duties of care: } \\
\text {-Educating patients with obesity } \\
\text { about weight-related comorbidities: }\end{array}$} \\
\hline Disagree & Reference & Reference \\
\hline Neutral & $17.5(-8.9 ; 44.0)$ & 0.19 \\
\hline Agree & $24.1(4.2 ; 44.0)$ & 0.02 \\
\hline \multicolumn{3}{|c|}{ Discussing weight: } \\
\hline Score 7-18 & Reference & Referencesss \\
\hline Score 19-20 & $-4.7(-16.1 ; 6.6)$ & 0.41 \\
\hline Score 21-22 & $0.1(-10.6 ; 10.8)$ & 0.98 \\
\hline Score $23-28$ & $10.5(-0.5 ; 21.4)$ & 0.06 \\
\hline Intercept & $19.6(-2.3 ; 41.5)$ & \\
\hline
\end{tabular}

lack of time as the most important cause. This result was in keeping with the findings of other studies [17,26] and comprehensible with the fact that Dutch GPs are paid per patient by the primary health care insurance cover, based on an average consultation time of 10 minutes [36]. However, by preventing weight-related diseases by means of optimal weight management, it is presumable that by referring to a weight management specialist, GPs could save time in the end.

Next, patients' lacking motivation was reported as a reason for GPs to not discuss patients' weight problem, neither refer the patient to a dietitian. But in fact, patients' lacking motivation is one of the main factors of failing weight management [37]. Therefore, patients' lacking motivation should be a signal to discuss patients' weight problem, use motivational interviewing and eventually refer to a specialized caregiver [37].

In contrast to other studies [26], only one third of the respondents reported costs as an important reason for not referring to other health care providers. In the Netherlands, costs may be of little importance due to the system of reimbursement of dietary treatment from Dutch primary health insurance cover. To date, three hours of dietary treatment is included in the standard health insurance package of all Dutch citizens which is obligatory for all Dutch citizens.

Remarkably, the presence of a dietitian in the same medical building was no indication for significantly higher referral rates. Problems in interdisciplinary communication are frequently mentioned in the literature $[17,24,25]$. The present findings indicate that GPs and dietitians should, even when they work in the same building, actively support frequent interdisciplinary communication, for example by providing face-to-face information about their processes [38].

This study has several limitations that may affect interpretation of the results. First, the number of non responders was substantial. In future studies, the response rate might be improved when using incentives, however, for the present study there was no budget available. Since web-based questionnaires appeared to result in higher response-rates $[39,40]$, this is a recommendation for future studies as well. The second limitation is that the validity and reliability of the questionnaire, though developed carefully, is unclear. Final limitation is the potential information bias. Possibly respondents have provided socially acceptable answers to the questions which may have resulted in a overestimation of the number of GPs with a healthy BMI and the frequency of discussing weight issues with patients. Studies that surveyed patients' experiences, reported that GPs only intervened in half of the cases with obesity $[11,12]$. The contrast between GPs' reporting and patients' experiences implicates for future studies that referral percentages need 
to be confirmed by using data from patient records. Other recommendations for further research are to assess the weight loss of patients referred to a dietitian in comparison to the weight loss of patients without a referral to a dietitian or to another health care provider in weight management.

The key strength of this study is the survey of GPs' perception of their overweight and obesity management policy. Besides examining GPs' self-reported frequency of discussing weight as well as their percentages for obesity management, we investigated factors associated with GPs' weight management policy. The representative population of GPs from all over the Netherlands strengthens the study's reliability.

In conclusion, this study showed that GPs' self-reported weight management policy is in accordance with the professional guideline. Nonetheless, in the context of prevention, discussing weight at an early stage of weight gain deserves more attention, especially for younger GPs. Education programs should emphasize the importance of discussing the influence of medication use, psychosocial problems and environmental factors on weight gain. To increase the referral percentage for obesity management, it is important for GPs and dietitians to strengthen interdisciplinary collaboration. Shared feelings of responsibility between GPs and specialists in dietary treatment could play a fundamental role in the struggle to beat overweight and obesity.

\section{Additional file}

Additional file 1: Table S1. Questionnaire. Table S2. Genera

characteristics from the NIVEL database.

\section{Competing interests}

The authors declare that they have no competing interests.

\section{Authors' contributions}

$\mathrm{JT}$, IS and CV were involved in the conception and design of the study. JT was involved with data collection. CK performed the statistical analysis and drafted the manuscript. All authors were involved in the interpretation of data and have critically reviewed the manuscript and have approved the final version submitted for publication.

\section{Acknowledgements}

We would like to thank Roisin de Jong for editing the manuscript. The study was funded by the Ministry of Health, Welfare and Sport.

\section{Author details}

${ }^{1}$ NIVEL Utrecht, PO Box 1568, 3500 BN, Utrecht, The Netherlands. ${ }^{2}$ VU University Medical Center Amsterdam, Amsterdam, The Netherlands.

Received: 19 September 2013 Accepted: 16 January 2014 Published: 19 February 2014

\section{References}

1. World Health Organization: Controlling the global obesity epidemic. 2003. [Webpage from the internet, checked on febr 14th, 2013] Availbable from http://www.who.int/nutrition/topics/obesity/en/
2. Centraal Bureau voor de Statistiek S: Length and Weight of people from 1981 till now. 2013. [Webpage from the internet, checked on Febr 13th, 2013]. Available from: http://statline.cbs.nl/StatWeb/publication/?DM=SLNL\&PA=81565NED.

3. Bemelmans WJE, Hoogenveen RT, Visscher TLS, Verschuren WMM, Schuit AJ: Toekomstige ontwikkelingen in overgewicht. Rapport 260301003. Bilthoven: RIVM; 2004.

4. Polder JJ, Takkern J, Meerding WJ, Kommer GJ, Stokx LJ: Kosten van ziekten in Nederland - De zorgeuro ontrafeld. Bilthoven: Rijksinstituut voor Volksgezondheid en Milieu; 2002.

5. World Health Organization: Obesity and Overweight. Fact sheet. 2012. [Webpage from the internet, checked on febr. 18th, 2013] Available from: http://www.who.int/mediacentre/factsheets/fs311/en/index.html.

6. Kolotkin RL, Meter K, Williams GR: Quality of life and obesity. Obes Rev 2001, 2:219-229.

7. Scott KM, Bruffaerts R, Simon GE, Alonso J, Angermeyer M, de Girolamo G, et al: Obesity and mental disorders in the general population: results from the world mental health surveys. Int J Obes (Lond) 2008, 32:192-200.

8. Verheij RA, Van Dijk CE, Stirbu-Wagner I: Landelijk Informatienetwerk Huisartsenzorg. Feiten en ciffers over huisartsenzorg in Nederland (in Dutch). Utrecht Nijmegen; 2009. [Webpage from the internet, checked on march 12th, 2013] Available from http://www.nivel.nl/linh-zorgregistratie-huisartsen.

9. van Dijk L, Otters HB, Schuit AJ: Moderately overweight and obese patients in general practice: a population based survey. BMC Fam Pract 2006, 7:43.

10. Van Binsbergen JJ, Langens FNM, Dapper ALM, Van Halteren MM, Glijsteen R, Cleyndert GA, Mekenkamp-Oei SN, Van Avendonk MJP: Huisarts Wet 2010, 53(11):609-625

11. Galuska DA, Will JC, Serdula MK, Ford ES: Are health care professionals advising obese patients to lose weight? JAMA 1999, 282:1576-1578.

12. Tham M, Young D: The role of the General Practitioner in weight management in primary care-a cross sectional study in General Practice. BMC Fam Pract 2008, 9:66.

13. Fogelman Y, Vinker S, Lachter J, Biderman A, Itzhak B, Kitai E: Managing obesity: a survey of attitudes and practices among Israeli primary care physicians. Int J Obes Relat Metab Disord 2002, 26:1393-1397.

14. Forman-Hoffman V, Little A, Wahls T: Barriers to obesity management: a pilot study of primary care clinicians. BMC Fam Pract 2006, 7:35.

15. Hiddink GJ, Hautvast JG, van Woerkum CM, Fieren CJ, van 't Hof MA: Nutrition guidance by primary-care physicians: perceived barriers and low involvement. Eur J Clin Nutr 1995, 49:842-851.

16. Morris SE, Lean ME, Hankey CR, Hunter C: Who gets what treatment for obesity? A survey of GPs in Scotland. Eur J Clin Nutr 1999, 53(Suppl 2):S44-S48.

17. Nicholas LG, Pond CD, Roberts DC: Dietitian-general practitioner interface: a pilot study on what influences the provision of effective nutrition management. Am J Clin Nutr 2003, 77:1039S-1042S.

18. Sonntag U, Brink A, Renneberg B, Braun V, Heintze C: GPs' attitudes, objectives and barriers in counseling for obesity-a qualitative study. Eur J Gen Pract 2012, 18:9-14

19. Visser F, Hiddink G, Koelen M, van Binsbergen J, Tobi H, van Woerkum C: Longitudinal changes in GPs' task perceptions, self-efficacy, barriers and practices of nutrition education and treatment of overweight. Fam Pract 2008, 25(Suppl 1):i105-i111.

20. Wynn K, Trudeau JD, Taunton K, Gowans M, Scott I: Nutrition in primary care: current practices, attitudes, and barriers. Can Fam Physician 2010, 56:e109-e116.

21. Flocke SA, Gilchrist V: Physician and patient gender concordance and the delivery of comprehensive clinical preventive services. Med Care 2005, 43:486-492

22. Ferrante JM, Piasecki AK, Ohman-Strickland PA, Crabtree BF: Family physicians' practices and attitudes regarding care of extremely obese patients. Obesity (Silver Spring) 2009, 17:1710-1716.

23. Pomeroy SE, Cant RP: General practitioners' decision to refer patients to dietitians: insight into the clinical reasoning process. Aust J Prim Health 2010, 16:147-153.

24. Mathus-Vliegen EMH: De "ideale diëtist" is flexibel en toegankelijk (in Dutch). The "ideal dietitian" is flexible and approachable. Ned Tijdschr Diëtisten 2006, 61:142-147.

25. Pomeroy SEM, Worsley A: Enhancing the dietary management of general practice patients through collaborative care: perspectives of general practitioners and dietitians. Nutr Diet 2009, 66:81-86.

26. Gunther S, Guo F, Sinfield P, Rogers S, Baker R: Barriers and enablers to managing obesity in general practice: a practical approach for use in implementation activities. Qual Prim Care 2012, 20:93-103. 
27. NIVEL: Beroepenregistratie Databank NIVEL. [Webpage from the internet, checked on may 23th, 2013] Available from http://www.nivel.nl/databank.

28. Longnecker MT, Lyman Ott R: An introduction to statistical methods and data analysis, 6 edn. Belmont CA, USA: Dusbury Resource Center; 2008.

29. Smith AW, Borowski LA, Liu B, Galuska DA, Signore C, Klabunde C, et al: U.S. primary care physicians' diet-, physical activity-, and weight-related care of adult patients. Am J Prev Med 2011, 41:33-42.

30. de Vries H, Mudde A, Leijs I, Charlton A, Vartiainen E, Buijs G, et al: The European Smoking Prevention Framework Approach (EFSA): an example of integral prevention. Health Educ Res 2003, 18:611-626.

31. Iversen LB, Strandberg-Larsen K, Prescott E, Schnohr P, Rod NH: Psychosocial risk factors, weight changes and risk of obesity: the Copenhagen City Heart Study. Eur J Epidemiol 2012, 27:119-130

32. Giskes $K$, van Lenthe F, Avendano-Pabon M, Brug J: A systematic review of environmental factors and obesogenic dietary intakes among adults: are we getting closer to understanding obesogenic environments? Obes Rev 2011, 12:e95-e106.

33. Brotons C, Ciurana R, Pineiro R, Kloppe P, Godycki-Cwirko M, Sammut MR: Dietary advice in clinical practice: the views of general practitioners in Europe. Am J Clin Nutr 2003, 77:1048-1051.

34. Puhl RM, Gold JA, Luedicke J, Depierre JA: The effect of physicians' body weight on patient attitudes: implications for physician selection, trust and adherence to medical advice. Int J Obes (Lond) 2013, 37(11):1415-1421.

35. van Dijk E, Kampen JK, Hiddink GJ, Renes RJ, van Binsbergen JJ, van Woerkum CM: A longitudinal study of changes in noticing and treating patients' overweight by Dutch GPs between 1997 and 2007. Fam Pract 2012, 29(Suppl 1):i61-i67.

36. Deveugele M, Derese A, van den Brink-Muinen A, Bensing J, De Maeseneer $\mathrm{J}$ : Consultation length in general practice: cross sectional study in six European countries. BMJ 2002, 325:472

37. Grave RD, Centis E, Marzocchi R, El Ghoch M, Marchesini M: Major factors for facilitating change in behavioral strategies to reduce obesity. Psychol Res Behav Manag 2013, 6:101-110.

38. Mitchell $\sqcup$, Macdonald-Wicks L, Capra S: Increasing dietetic referrals: perceptions of general practitioners, practice nurses and dietitians. Nutr Diet 2012, 69:32-38.

39. Touvier M, Méjean C, Kesse-Guyot E, Pollet C, Malon A, Castetbon K, et al: Comparison between web-based and paper versions of a self-administered anthropometric questionnaire. Eur J Epidemiol 2010, 25:287-296.

40. Vergnaud AC, Touvier M, Méjean C, Kesse-Guyot E, Pollet C, Malon A, et al: Agreement between web-based and paper versions of a sociodemographic questionnaire in the NutriNet-Santé study. Int J Public Health 2011, 56:407-417.

doi:10.1186/2052-9538-1-2

Cite this article as: Kloek et al.: Dutch General Practitioners' weight management policy for overweight and obese patients. BMC Obesity $20141: 2$

\section{Submit your next manuscript to BioMed Central and take full advantage of:}

- Convenient online submission

- Thorough peer review

- No space constraints or color figure charges

- Immediate publication on acceptance

- Inclusion in PubMed, CAS, Scopus and Google Scholar

- Research which is freely available for redistribution 